\title{
A PERSPECTIVA DOS EXPATRIADOS SOBRE ASPECTOS DO AMBIENTE INSTITUCIONAL QUE INFLUENCIAM SUAS CONDIÇÕES DE VIDA NOS PAÍSES HOSPEDEIROS
}

\author{
Mariana Rangel Moraes, ${ }^{1}$ Márcia Zabdiele Moreira, Diego de Queiroz Machado \& Daniel Barboza Guimarães \\ Universidade Federal do Ceará -UFC, Ceará, (Brasil)
}

DETALHES DO ARTIGO
Histórico do Artigo:
Recebido em: 17 de setembro de 2020
Aceito: 01 de outubro de 2021
Disponível online: 27 de outubro de 2021
Sistema de revisão "Double blind review"
Editor Científico
llan Avrichir

Palavras-chaves:

Expatriação

Condições de Vida no Exterior

Ambiente Institucional

Países Hospedeiros

\begin{abstract}
RESUMO
Objetivo: o estudo teve o objetivo de analisar a perspectiva dos expatriados sobre aspectos do ambiente institucional que influenciam suas condições de vida nos países hospedeiros.
\end{abstract}

Método: tratou-se de uma pesquisa quantitativa, com dados secundários obtidos a partir do relatório HSBC Expat Explorer Broadening perspectives, publicado em 2017. Realizou-se análise de cluster, para agrupamento dos países sobre nove variáveis relativas aos aspectos econômicos, de experiência e de família. Validaram-se os resultados obtidos por meio de análise discriminante.

Principais resultados: constatou-se a existência de três agrupamentos, um com uma maior valorização dos aspectos de experiência, outro com valorização equivalente dos aspectos de experiência e econômicos e outro com maior valorização de aspectos de família.

Relevância/originalidade: como as condições de vida em outros países podem influenciar o ajustamento intercultural do expatriado e a duração da expatriação, podendo inclusive culminar em uma repatriação antecipada, este estudo se faz relevante e original por relacionar temas que, geralmente, são estudados em separado: fatores institucionais dos países, condições de vida nos países e expatriação.

Contribuições teóricas/metodológicas: o estudo amplia as discussões ao considerar a perspectiva dos expatriados sobre como os fatores institucionais dos países hospedeiros influenciam as condições de vida que terão alhures.

\section{INTRODUÇÃO}

Os desafios de gestão internacional emergiram devido à forte intensificação da internacionalização pelo qual passaram muitas companhias, com destaque para o impacto da diversidade cultural na gestão internacional. Culturas nacionais e organizacionais, sistemas de negócios e gestão diversos, práticas e processos organizacionais particulares e negociação e estratégias diferentes são apenas algumas das variáveis com que as empresas têm que lidar quando decidem expandirse internacionalmente (Tanure, \& Duarte, 2006).

Dispor de um contingente capaz e preparado para lidar com os vários aspectos de uma internacionalização é imprescindível ao sucesso de uma organização em uma empreitada desse porte, como afirmam Carpes et al. (2012). Em 2013, havia, aproximadamente, 52,8 milhões de expatriados no mundo e 66,2 milhões em 2017, representando uma taxa de crescimento de $5,8 \%$ no período. Estima-se que, em 2021, o número de expatriados alcance um total por volta de 87,5 milhões. Com esse crescimento nas designações internacionais, as estratégias de expatriação se tornaram essenciais para as empresas com atuação internacional (FINACCORD, 2018).

Os fatores institucionais, que interferem diretamente na forma como os negócios são realizados em determinado local, podem ser tanto 
formais como informais. Os fatores formais se referem às leis e aos regulamentos, enquanto os fatores informais, as normas e a cultura dos países. Assim, entende-se que a Teoria Institucional é de suma importância a qualquer organização, sobretudo aquelas que atuam fora de seu território de origem, uma vez que os fatores formais e, principalmente, informais se alteram bastante de um país para outro. Um estudo aprofundado dos fatores institucionais da nação e, posteriormente, a elaboração de uma estratégia de abordagem apropriada são imprescindíveis, portanto, antes de se iniciar o processo de internacionalização da empresa e possíveis expatriações (Peng, Sun, Pinkham, \& Chen, 2009).

Sambavisan, Sadoughi e Esmaeilzadeh (2017) destacam que os fatores que mais influenciam o ajustamento intercultural dos expatriados são fatores relacionados à empatia cultural, inteligência cultural e suporte ao cônjuge. Nesse sentido, os fatores institucionais dos países precisam ser mais explorados nas pesquisas, quanto à maneira como se dão as contribuições dos fatores institucionais, organizacionais e do indivíduo nesse ajustamento.

Peng et al. (2009) destacam que até a metade da década de 1990, poucas eram as contribuições literárias para uma visão mais institucional, de modo que, raramente, os autores se dedicavam a dissertar acerca da relação entre instituições, organizações e estratégias. Consequentemente, as empresas, na maioria das vezes, desconsideravam a importância de uma atuação que também fosse baseada em estruturas institucionais, o que fazia com que, tanto os fatores formais quanto os informais fossem deixados para segundo plano ou, na melhor das hipóteses, fossem tratados como fatores de fácil manipulação e controle por parte das organizações.

O marco dessa teoria é o institucionalismo e a qualidade das instituições que controlam e interferem no desempenho econômico e social de um território ou país (Brunozi, Antunes, Kronbauer, \& Deboçã, 2016). Os expatriados avaliam e comparam o ambiente institucional dos países em busca de um lugar favorável, tanto para seu desenvolvimento de carreira quanto para sua vida pessoal, onde possam ter melhores condições de vida.

O principal objetivo deste estudo, portanto, consiste na perspectiva dos expatriados sobre aspectos do ambiente institucional dos países que influenciam suas condições de vida nos países hospedeiros. Definiram-se como objetivos específicos: (a) identificar como os expatriados avaliam o ambiente institucional dos países quanto aos aspectos econômicos, experiência e vida familiar;

(b) agrupar os países, a partir de suas diferenças e semelhanças, em relação aos aspectos econômicos, experiência e vida familiar.

Para tanto, utilizou-se de uma abordagem quantitativa de pesquisa, mediante dados secundários extraídos do relatório intitulado HSBC Expat Explorer Broadening perspectives. A unidade de análise consistiu em um universo de 46 países, para o ano de 2017, que fazem parte da pesquisa sobre expatriação realizada pelo Hong Kong and Shanghai Banking Corporation (HSBC), cuja publicação mais recente é de 2017 (HSBC, Expat, 2017). Para tratamento dos dados utilizou-se análise de clusters pelo método hierárquico do vizinho mais distante e, finalmente, foi realizada análise discriminante para validar os resultados dos agrupamentos definidos.

Como as condições de vida em outros países podem influenciar o ajustamento intercultural do expatriado e a duração da expatriação, podendo inclusive culminar em uma repatriação antecipada, este estudo se faz relevante por relacionar temas que, usualmente, são estudados em separado: fatores institucionais dos países, condições de vida nos países hospedeiros e expatriação. Pesquisas que relacionam esses temas se concentram, particularmente, no estudo da distância cultural e distância institucional entre o país de origem e o país hospedeiro.

\section{AMBIENTE INSTITUCIONAL E CONDIÇÕES DE VIDA DOS EXPATRIADOS NOS PAÍSES HOSPEDEIROS}

Principalmente, até a década de 1940, a análise dos ambientes organizacionais era ainda muito restrita à perspectiva objetiva, ou seja, era 
essencialmente concentrada nos aspectos organizacionais objetivos, como recursos materiais, tecnológicos e capitais. Após os trabalhos de Selznick (1971), publicados a partir de 1948, ganha força uma abordagem mais institucional, que leva em consideração uma perspectiva organizacional mais ampla, contando com os fatores sociais, econômicos e culturais do ambiente.

A partir do final da década de 1990, compreende-se cada vez mais a necessidade de se utilizar diversas teorias na análise organizacional, que possuam um enfoque mais abrangente, contando impreterivelmente com a abordagem institucional. 0 estudo e entendimento de ambos os ambientes, interno e externo, passam a ocupar espaço de destaque na composição da análise de uma organização como um todo, auxiliando na eliminação de incertezas e suposições (Rossetto, \& Rossetto, 2005).

Scott (2014) elucida que as instituições têm duas características marcantes: (i) limitam e direcionam os comportamentos dos indivíduos em uma sociedade; (ii) diferenciam os grupos de indivíduos, dando privilégios, papéis e responsabilidades diferentes a diferentes atores e grupos de atores. Os expatriados, enquanto atores que atuam em diferentes ambientes culturais e institucionais, vivenciam no dia a dia os desafios inerentes à adaptação a essa diversidade de ambientes e buscam aproveitar as oportunidades de desenvolvimento de carreira e ganho de qualidade de vida a partir das vantagens que o ambiente institucional dos países pode oferecer.

\subsection{Ambiente institucional dos países}

Meyer e Rowan (1977) sustentam que muitas estruturas organizacionais formais resultam de um conjunto de regras institucionais e racionalizadas. Assim, o aumento da complexidade e a expansão dessas estruturas organizacionais formais são atendidas, parcialmente, pela criação desse conjunto de regras institucionais, tanto implícitas como explícitas.

O ambiente institucional pressiona as organizações a adaptarem-se às suas expectativas e princípios, para desenvolverem legitimidade entre seus stakeholders e, assim, facilitar a interação das organizações com as partes interessadas, por exemplo, a cooperação dos funcionários, incluindo-se os expatriados, as preferências dos clientes e a entrega de recursos dos fornecedores (Ranieri, 2018).

North (1990) deu às instituições a alcunha "as regras do jogo", no intuito de atribuir a elas o papel de definir e criar as restrições as quais moldam as interações humanas, como a estruturação de incentivos políticos, sociais e econômicos que definem as trocas humanas. Em outras palavras, as instituições moldam a evolução das sociedades, sendo imprescindíveis para o entendimento do histórico de mudanças e evoluções do mundo.

O autor também atribuiu às instituições a função de reduzir a incerteza em razão de proporcionarem à sociedade uma estrutura estável e comum à vida cotidiana. Como as instituições definem a forma como a interação humana ocorre, os membros da sociedade possuem o conhecimento de como realizam os procedimentos comuns à sua rotina, por exemplo, como dirigir um veículo, como comprar alimentos e como obter dinheiro emprestado. Essas atividades, embora pareçam banais para a grande maioria dos cidadãos de um país, podem ser completamente diferentes quando comparadas a outros países.

Brunozi et al. (2016) complementam que as regras do jogo condicionam o comportamento humano. O indivíduo e as instituições, que são criações humanas, evoluem ao longo do tempo por meio de um processo de aprendizado cumulativo, em que as instituições moldam as preferências e os valores dos indivíduos - hábitos mentais são herdados e tendem a persistir, transmitidos de geração para geração.

As decisões estratégicas, decorrentes da inclusão da visão institucional como parte da estratégia organizacional, são resultantes da interação dinâmica entre as organizações e as instituições (Peng, 2002). As instituições podem ser tanto formais, como as leis de um determinado país, como informais, como convenções e códigos de comportamentos. Independentemente do tipo de instituição, essa pode ter sido criada, como a 
constituição de um país, ou pode ter evoluído com o tempo, como os costumes (North, 1990).

Segundo a corrente conhecida como Novo Institucionalismo, as instituições formais são fortes influenciadoras do comportamento econômico e social, ajudando a moldar as ações econômicas e o modo como a sociedade se organiza. $\mathrm{O}$ intuito das instituições formais ao influenciarem no modo como a sociedade se organiza é ter o controle sob a estrutura de incentivos da sociedade, podendo conduzi-lo em seu favor. Não se deve, no entanto, desconsiderar-se a importância dos instrumentos institucionais informais, como, crenças e convenções, como influenciadores das ações das empresas (Lee, 2011).

Scott (2014) entende as instituições como um conjunto de estruturas e atividades de cunho regulativo, normativo e cognitivo, as quais proporcionam estabilidade e sentido ao comportamento social. Nesse sentido, os três pilares que ofereciam suporte a essas instituições seriam: o regulativo, o normativo e o cognitivo. Complementarmente a visão do autor, North (1990) classifica as instituições como formais e informais. A aplicação de fatores institucionais, formais e informais, abrange vários aspectos da organização. A elaboração de políticas de Gestão de Pessoas, por exemplo, é extremamente influenciada por esses fatores (Lacombe, \& Chu, 2008).

Peng (2013) procurou aprofundar os estudos acerca das diferentes instituições, consolidando a classificação mais aceita dessas em formais e informais. O trabalho do autor foi muito além de defini-las e classificá-las, buscou-se, portanto, entendê-las e compreender como influenciam tão fortemente as mais diferentes nações, sem perder de vista os três pilares básicos da Teoria Institucional.

O pilar regulativo sustenta as instituições formais à medida que permite a utilização do poder coercivo em prol dos governos. As instituições informais, compostas por normas, culturas e éticas, são suportadas pelos outros dois pilares, o normativo e o cognitivo. O pilar normativo refere-se à influência que crenças, valores e atitudes tomadas por atores importantes do cenário exercem sobre indivíduos e firmas, em geral. Outra estrutura de suporte às instituições informais, o pilar cognitivo, refere-se à internalização, muitas vezes até não percebida, de valores e crenças por indivíduos de forma a moldar seus comportamentos (Peng, 2013).

Os expatriados percebem no dia a dia o ambiente institucional formado pelos pilares regulativo, normativo e cognitivo, que influenciam a forma como a sociedade se organiza no país hospedeiro diferentemente do país de origem. Os diferentes incentivos e aspectos críticos são percebidos pelos expatriados entre os diversos países. Além dos fatores formais, também os informais são notados pelos expatriados quando pensam em buscar uma expatriação para determinado país ou quando declinam de experiências de trabalhos por não perceberem vantagens oferecidas por outros países.

\subsection{Expatriação e condições de vida dos expatriados no exterior}

A expatriação é tema oriundo da área de Gestão Internacional de Recursos Humanos (GIRH). Para acompanhar o estágio de globalização avançado em que se encontra o mundo, é imprescindível que as multinacionais possuam um contingente humano que promova suporte a essa evolução. Assim, torna-se necessário dispor de profissionais de alto nível capazes de atuarem além das fronteiras nacionais da empresa (Caligiuri, Hyland, \& Joshi, 1998; Caligiuri, 2000). As organizações possuem planos de carreira internacionais que contribuem na resposta a essa necessidade de desenvolvimento de competências globais que o mercado exige, exercendo a expatriação um papel de destaque (Tanure, \& Duarte, 2006).

Os expatriados são colaboradores enviados ao exterior, para viver e trabalhar, pelas organizações em que atuam no país de origem, pelo período de um ano ou mais anos com o intuito de desenvolver competências globais e participar do desenvolvimento da companhia como um todo, atuando em suas subsidiárias estrangeiras (Caligiuri, 1997).

Outros autores conceituam o termo expatriado segundo diferentes perspectivas, como é o caso de 
Harrison, Shaffer e Bhaskar-Shrinivas (2004), que atrelam a ida de um profissional ao exterior com o intuito de cumprir uma missão específica da organização em que atua no país de origem. Bonache (2002) frisa que para que um indivíduo seja considerado expatriado, esse precisa cumprir pelo menos dois requisitos principais: primeiramente, mudar-se para um país distinto daquele que possui origem com o intuito de desempenhar atividade profissional similar à que desenvolve antes da transferência; além disso, essa transferência não pode ser por um período demasiadamente curto de maneira que suas consequências não afetem fortemente a vida do indivíduo.

O fenômeno da expatriação é bastante diversificado por abranger pessoas de inúmeras profissões e nacionalidades. Essas pessoas assemelham-se, todavia, em relação a um sentimento em comum observado, o desejo pela mudança. González e Oliveira (2011) ainda destacam que, na maioria das vezes, a iniciativa pela expatriação parte muito mais do funcionário, decorrente desse anseio de mudar, do que da própria empresa, observando-se, portanto, uma espontaneidade na decisão, tornando-a ainda mais genuína.

O recrutamento é a etapa posterior à definição de quantos e quais candidatos se necessita para preencher uma lacuna identificada na empresa. Para que o processo posterior ao recrutamento, a seleção, possa ser realizada, é necessário que tenham sido recrutados candidatos tanto em número suficiente quanto que atendam às qualidades exigidas. No caso da expatriação, o recrutamento pode assumir um papel crucial ao sucesso da empresa no exterior, especialmente quando a subsidiária estrangeira esteja localizada em países em desenvolvimento, onde seja mais complicado se encontrar profissionais com alta qualificação (Dowling, Festing, \& Engle, 2013).

É importante que a empresa que se proponha a investir em expatriação compreenda que é um processo bastante arriscado e que o retorno não é garantido: tanto o indivíduo pode não render o que se espera, como pode acabar retornando antes, desistindo de concluir a experiência. O caráter oneroso é devido a todo o suporte financeiro que o colaborador necessita para que possa se estabelecer, juntamente com sua família, no país estrangeiro; esse processo ainda é, também, dificultado por toda a necessidade de auxílio não financeiro, que tanto esse expatriado como sua família necessitam antes da partida, durante a estadia e após o retorno (Dutra, 2012).

Os profissionais de Recursos Humanos devem estar atentos na seleção de expatriados, pois uma seleção eficiente pode evitar uma série de problemas de variadas dimensões, como técnica, cultural e interpessoal, podendo evitar a repatriação, a frustração dos objetivos pretendidos com a expatriação e a perda de tempo e recursos financeiros investidos (Snell, \& Bohlander, 2013). Mesmo se tratando de uma filial da mesma empresa, o contexto em que ele é inserido é bastante diferenciado, não somente em relação ao ambiente interno da organização, como em relação ao ambiente externo, já que tanto o lugar é outro como também são, geralmente, a cultura, as experiências e o ritmo de vida, o que impacta não somente a vida do colaborador, como de sua família, quando o acompanha (Hill, 2011).

No contexto da expatriação, o recrutamento e a seleção precisam ser reforçados com uma preparação adequada do futuro expatriado antes de efetivamente deixar o seu país. Após a seleção dos candidatos, aconselha-se que a empresa exponha, novamente, os objetivos que pretende atingir com essa expatriação, o que espera do indivíduo, a realidade que tanto expatriado quanto a família vão enfrentar, as vantagens e as desvantagens desse processo e, não menos importante, as condições que devem enfrentar no retorno (Tanure, \& Duarte, 2006).

Hill (2011) afirma que apenas 30\% desses profissionais recebem treinamento antes da partida. O ideal seria a realização de três tipos de treinamento: cultural, linguístico e prático. Dowling, Festing e Engle (2013) enfatizam a importância do cônjuge e do restante da família do expatriado também passarem por esses treinamentos. $\mathrm{O}$ ajustamento intercultural se refere ao grau de conforto psicológico e adaptação dos expatriados ao trabalharem e viverem no país para onde foram conduzidos pela matriz (Caligiuri, 1997). Assim, Zhang e Rentz (1996) afirmam que o 
ajustamento intercultural eficiente aconteceria quando o indivíduo estivesse apto a viver no novo ambiente de uma maneira totalmente adaptada, de forma a sentir conforto similar como sente ao viver no ambiente de origem.

Mendenhall e Oddou (1985) destacam que a capacidade de se comunicar e de interagir do expatriado configura-se como uma característica que facilita o alcance de um sucesso do processo de expatriação, à medida que auxilia a integração do expatriado com os companheiros de trabalho e demais nativos. Muitas vezes menosprezada, porém uma etapa tão importante quanto as anteriores, é a repatriação, isto é, o retorno do expatriado à organização de origem em seu país, após um período de realização de uma missão internacional em uma subsidiária estrangeira (Snell, \& Bohlander, 2013).

A repatriação, com certa frequência, acaba sendo negativa, já que muitas vezes a experiência do repatriado não é valorizada como deveria, seu cargo pode ter sido extinto, o profissional adquiriu novas habilidades durante a expatriação, o que deveria ser algo benéfico, mas pode dificultar ainda mais a sua recolocação na empresa novamente (Hill, 2011).

Em se tratando especificamente do contexto de expatriação, um dos fatores institucionais formais que mais influencia na condição de vida do expatriado é o arcabouço jurídico que compõe todo o regulamento formal. Tanto os sistemas legais do país de origem como da nação hospedeira, exercem importante papel no que diz respeito aos direitos dos expatriados e famílias. 0 sentimento de segurança em relação ao cumprimento desses direitos traz uma situação positiva quanto à experiência de expatriação como um todo (Gallon, Cerutti, \& Maciel, 2018).

Os sistemas econômicos também compreendem fatores institucionais formais comumente apontados por expatriados como fundamentais à decisão de aceitar o desafio da expatriação. Embora os transtornos decorrentes do processo sejam inevitáveis, acabam sendo, muitas vezes, superados pela possibilidade de multiplicar os rendimentos em países que propiciam maiores oportunidades, para isso associada a benefícios, como ajuda de custo.
Mesmo não sendo o único motivo que leva um indivíduo a aceitar viver e trabalhar em outro país, o fator econômico não pode ter sua importância subestimada (Tertuliano, 2016).

Em relação às instituições informais, há grande destaque no que se refere a um aspecto intrinsecamente dependente da cultura local: o idioma. Foca-se muito no fato de o expatriado dominar o idioma do país de destino, entretanto fator igualmente importante ao sucesso da experiência é se observar se o país onde ocorrerá a expatriação possui um alto número de falantes de inglês, por exemplo, idioma considerado universal. Além disso, é importante observar se são oferecidos serviços em idiomas que facilitem o acesso e/ou utilização por estrangeiros (Cota, Emmendoerfer, \& Reis, 2015).

\section{MÉTODO DA PESQUISA}

Quanto à abordagem, a presente pesquisa é classificada como quantitativa, por apresentar resultados que podem ser quantificados, dando menor espaço à percepção e à interpretação, características das pesquisas qualitativas. A pesquisa quantitativa é essencialmente objetiva, o que também se contrapõe à abordagem qualitativa, recorrendo a procedimentos matemáticos, para apontar relações entre variáveis e explicar fenômenos e suas causas (Fonseca, 2002).

A pesquisa caracterizou-se, também, como estudo descritivo, bibliográfico e documental. Utilizaram-se de dados secundários para a realização da pesquisa. Os dados secundários são oriundos do HSBC Expat Explorer Broadening perspectives, elaborado pelo HSBC Expat (2017). Esse relatório apresenta dados numéricos, análises e conclusões acerca da relação entre três fatores institucionais: fatores relativos à economia, à experiência individual e aos aspectos familiares. O relatório apresenta, na perspectiva dos expatriados, os fatores mais favoráveis à expatriação,

em um grupo de 46 países analisados, em 2017, sendo estes países o universo de análise do presente estudo. 
Perspectiva dos Expatriados sobre Aspectos do Ambiente Institucional que Influenciam suas Condições de Vida nos Países Hospedeiros

As variáveis analisadas na presente pesquisa foram definidas de acordo com as variáveis divulgadas no Relatório HSBC Expat (2017) e estão apresentadas no Quadro 1.

\begin{tabular}{|l|l|}
\hline \multicolumn{1}{|c|}{ Variáveis do estudo } & \multicolumn{1}{c|}{ Descrição } \\
\hline Fatores relativos à Economia & Foco na economia dos países e no efeito desta sob os expatriados \\
\hline Personal Finances & $\begin{array}{l}\text { Perspectiva de ganhos, nível de renda disponível e perspectiva da } \\
\text { economia; }\end{array}$ \\
\hline Local Economy & $\begin{array}{l}\text { Confiança na economia local, visão acerca da estabilidade política e do } \\
\text { quão fácil é empreender no país; }\end{array}$ \\
\hline Working Life & $\begin{array}{l}\text { Perspectivas acerca de progressão na carreira, balanceamento entre } \\
\text { vida pessoal e trabalho e segurança no emprego. }\end{array}$ \\
\hline Fatores relativos à Experiência & Estilo de vida dos expatriados \\
\hline Lifestyle & Cultura local, saúde física e qualidade de vida; \\
\hline People & $\begin{array}{l}\text { Como as pessoas do país interagem com os expatriados e como elas se } \\
\text { sentem convivendo com essas pessoas, se conseguem se integrar e fazer } \\
\text { amizade com elas facilmente; }\end{array}$ \\
\hline Setting Up & $\begin{array}{l}\text { Organização relacionada às finanças, aspectos de saúde e aspectos } \\
\text { logísticos, como achar acomodação, quando efetivamente se mudam } \\
\text { para o país. }\end{array}$ \\
\hline Fatores relativos à Família & Família e vida familiar no país de expatriação \\
\hline Relationships & $\begin{array}{l}\text { Vida social dos expatriados, se eles se sentem próximos aos seus } \\
\text { parceiros e o quão aberto consideram que seja o país à diversidade; }\end{array}$ \\
\hline Education and Childcare & $\begin{array}{l}\text { Qualidade do cuidado com crianças, qualidade da educação e o custo } \\
\text { para se criar filhos; }\end{array}$ \\
\hline Raising Children & $\begin{array}{l}\text { Saúde e bem-estar dos filhos, a facilidade das crianças fazerem amizade } \\
\text { e a qualidade de vida para elas, em geral. }\end{array}$ \\
\hline
\end{tabular}

Quadro 1. Fatores institucionais analisados na pesquisa.

Fonte: Adaptado de HSBC Expat (2017).

A análise dos dados foi realizada em duas etapas: (i) análise de cluster e (ii) análise discriminante. De maneira geral, a análise de cluster é uma metodologia de classificação baseada em métodos numéricos, sendo utilizada com o objetivo de reduzir a quantidade de objetos de maneira que fiquem reunidos em clusters, como são denominados os agrupamentos. Em um mesmo cluster, devem estar reunidos elementos que possuem maior semelhança do que os objetos reunidos em demais clusters. Sendo assim, o resultado final é diretamente relacionado e dependente das variáveis utilizadas, visto que são a base da mensuração da similaridade entre os membros de um mesmo cluster. A alteração de variáveis ocasiona, portanto, grandes impactos sobre o resultado final (Corrar, Paulo, \& Dias, 2014).

Primeiramente, utilizou-se a técnica de análise de cluster pelo método hierárquico do vizinho mais distante (Hair, Anderson, Tatham, \& Black, 2005; Corrar, Paulo, \& Dias, 2014), visando o melhor agrupamento para os 46 países a partir dos fatores institucionais que influenciam as condições de vida dos expatriados nos países hospedeiros. Posteriormente, utilizou-se a análise discriminante como uma técnica confirmatória da análise de cluster (Hair, Anderson, Tatham, \& Black, 2005; Fávero, Belfiore, Silva, \& Chan, 2009).

\section{RESULTADOS E DISCUSSÕES}

A análise de cluster teve o intuito de agrupar os 46 países em grupos cujos integrantes apresentassem valores semelhantes para as variáveis aqui utilizadas e foi realizada a partir do método hierárquico do vizinho mais distante.

O planejamento de aglomeração explicitou a existência de três clusters. De acordo com a divisão proposta pela associação do cluster, os 46 países ficaram divididos de acordo com os seguintes agrupamentos, apresentados na Figura 1. 


\begin{tabular}{|l|l|l|}
\hline \multicolumn{1}{|c|}{ Cluster 1 (10 países) } & \multicolumn{1}{|c|}{ Cluster 2 (13 países) } & \multicolumn{1}{c|}{ Cluster 3 (23 países) } \\
\hline Argentina, Brasil, França, Itália, & Austrália, Áustria, Canadá, & Bahrain, Bélgica, China, Egito, \\
Quênia, Portugal, África do Sul, & República Tcheca, Alemanha, & Hong Kong, Indonésia, Irlanda, \\
Espanha, Tailândia e Turquia. & Índia, Holanda, Nova Zelândia, & Japão, Kuwait, Malásia, México, \\
& Noruega, Singapura, Suécia, & Oman, Peru, Filipinas, Polônia, \\
& Suíça e Emirados Árabes & Qatar, Rússia, Arábia Saudita, \\
& Unidos. & Coreia do Sul, Taiwan, Reino \\
& & Unido, Estados Unidos e \\
& Vietnam. \\
\hline
\end{tabular}

Figura 1. Clusters de países da pesquisa.

Fonte: Elaborado pelos autores a partir dos resultados da pesquisa (2020).

Após a análise de cluster, realizou-se uma análise discriminante para verificar quais variáveis impactavam, realmente, no processo de classificação dos países entre os grupos e confirmar a classificação obtida pela análise de cluster. Essa técnica apresenta dois pressupostos: normalidade e homogeneidade da matriz de covariância. Tanto os testes de KolmogorovSmirnov como o de Shapiro-Wilk confirmaram a normalidade das variáveis utilizadas, no entanto, o teste de Box's M apontou para a rejeição da hipótese nula de homogeneidade da matriz de covariância a 5\% (Sig. > 0,023), o que constitui uma quebra do prerrequisito da análise discriminante.
Contudo, de acordo com Fávero, Belfiore, Silva e Chan (2009), a rejeição, tanto da suposição de normalidade como da de homogeneidade da matriz de covariância, é aceitável para casos em que o número de variáveis presentes no modelo é menor que o número de observações pertencentes ao grupo com o menor número de elementos. Como, no presente trabalho, o menor cluster (cluster 1) é composto por 10 países, maior que o número de variáveis utilizadas (9), a análise discriminante permanece robusta, mesmo nas situações em que as hipóteses supracitadas sejam violadas.

A Tabela 1 apresenta os valores dos lambdas de Wilks para cada uma das variáveis utilizadas.

Tabela 1. Lambdas de Wilks das Variáveis Utilizadas

\begin{tabular}{l|l|l}
\hline Variáveis & Lambda de Wilks & Sig. \\
\hline Personal Finances & 0,659 & 0,000 \\
\hline Local Economy & 0,194 & 0,000 \\
\hline Working Life & 0,426 & 0,000 \\
\hline Lifestyle & 0,579 & 0,000 \\
\hline People & 0,862 & 0,041 \\
\hline Setting up & 0,904 & 0,115 \\
\hline Relationships & 0,902 & 0,109 \\
\hline Education and Childcare & 0,752 & 0,002 \\
\hline Raising Children & 0,405 & 0,000 \\
\hline
\end{tabular}

Fonte: Elaborada pelos autores a partir dos resultados da pesquisa (2020).

Identifica-se, a partir da tabela 1, que somente as variáveis Setting Up e Relationships não se mostraram estatisticamente significantes (Sig. $>0,10$ ), ou seja, elas não influenciam na classificação dos países pertencentes à amostra. Dentre as variáveis significantes, a que apresenta um maior poder de discriminação é Local Economy, uma vez que possui o 
menor valor de lambda de Wilks, seguida pelas variáveis Raising Children e Working Life.

A análise discriminante ainda permite a estimação de funções discriminantes. Como no presente estudo pretende-se verificar se realmente existem 3 grupos, conforme apontado pela análise de cluster, foram estimadas duas funções discriminantes, uma vez que o número de funções é dado pelo número de grupos menos um.

De acordo com os resultados obtidos, as duas funções se mostraram significantes (Sig. < 0,05) no tocante à discriminação entre os grupos, no entanto, a função 1 se apresenta com um maior poder de discriminação, quando comparada à função 2, sendo capaz de explicar 76,5\% das diferenças entre os grupos. Ao passo que a função 2 explica somente $23,5 \%$.

Diante da constatação de que a função 1 é a mais discriminante, verificou-se que as variáveis Local
Economy e Working Life são as mais relevantes nesta função, ratificando o fato de que estas variáveis já haviam se mostrado como mais discriminantes, uma vez que estas apresentaram menores valores para o lambda de Wilks. Além disso, a análise discriminante confirmou a classificação obtida pela análise de clusters, uma vez que $100 \%$ das observações foram classificadas corretamente.

\subsection{Identificação dos agrupamentos}

Diante da constatação e da validação da divisão dos 46 países componentes da amostra em 3 clusters, realizou-se uma análise descritiva dos dados para verificar as características em cada um dos 3 agrupamentos. A tabela 2 apresenta a média e o desvio-padrão de cada uma das variáveis, em cada cluster e no universo de países. 
Tabela 2. Estatísticas dos Grupos

\begin{tabular}{|c|c|c|c|c|}
\hline Cluster & Variáveis & Média & $\begin{array}{l}\text { Desvio- } \\
\text { Padrão }\end{array}$ & Amostra \\
\hline \multirow{9}{*}{1} & Personal Finances & ,396000 & ,0719877 & 10 \\
\hline & Local Economy & ,265000 & 0856673 & 10 \\
\hline & Working Life & ,372000 & ,0606996 & 10 \\
\hline & Lifestyle &, 549000 & ,0951548 & 10 \\
\hline & People & ,549000 & ,0803396 & 10 \\
\hline & Setting up & ,447000 & ,0933393 & 10 \\
\hline & Relationships & ,419000 & ,0602679 & 10 \\
\hline & Education and Childcare & , 391000 & ,0532186 & 10 \\
\hline & Raising Children & 496000 & ,0631049 & 10 \\
\hline \multirow{9}{*}{2} & Personal Finances &, 541538 & , 1083856 & 13 \\
\hline & Local Economy &, 662308 & ,0535652 & 13 \\
\hline & Working Life &, 586154 & ,0665255 & 13 \\
\hline & Lifestyle &, 561538 & ,0421992 & 13 \\
\hline & People & ,592308 & ,0518256 & 13 \\
\hline & Setting up &, 480000 & ,0835663 & 13 \\
\hline & Relationships & ,394615 & ,0694761 & 13 \\
\hline & Education and Childcare &, 456923 & 0997818 & 13 \\
\hline & Raising Children & ,573077 & ,0649852 & 13 \\
\hline \multirow{9}{*}{3} & Personal Finances &, 570870 & ,1031289 & 23 \\
\hline & Local Economy &, 431304 & 0751546 & 23 \\
\hline & Working Life & ,429565 & , 0800272 & 23 \\
\hline & Lifestyle & 436087 & 0756631 & 23 \\
\hline & People &, 533913 & ,0635852 & 23 \\
\hline & Setting up &, 420435 & , 0734524 & 23 \\
\hline & Relationships & ,361304 & ,0809772 & 23 \\
\hline & Education and Childcare & ,354348 & ,0737826 & 23 \\
\hline & Raising Children & ,393478 & ,0685306 & 23 \\
\hline \multirow{9}{*}{ Total } & Personal Finances &, 524565 & , 1192515 & 46 \\
\hline & Local Economy &, 460435 & 1602769 & 46 \\
\hline & Working Life &, 461304 & , 1088038 & 46 \\
\hline & \begin{tabular}{|l} 
Lifestyle \\
\end{tabular} & ,496087 & ,0937249 & 46 \\
\hline & People &, 553696 & ,0679660 & 46 \\
\hline & Setting up &, 443043 & 0830761 & 46 \\
\hline & Relationships & ,383261 & 0760717 & 46 \\
\hline & Education and Childcare & ,391304 & ,0884586 & 46 \\
\hline & Raising Children & ,466522 & 1020722 & 46 \\
\hline
\end{tabular}

Fonte: Elaboração própria a partir dos dados da pesquisa (2020).

No primeiro cluster, observa-se que as variáveis que apresentam as maiores médias são Lifestyle, People e Raising Children. Nesse cluster, identificouse, inicialmente, portanto, uma tendência econômica menos expressiva em detrimento de um maior destaque aos aspectos relacionados à qualidade de vida pessoal e familiar e às relações interpessoais.

O segundo cluster, por sua vez, possui a variável Local Economy como a de maior média, indicando que há uma tendência entre os expatriados dos países deste grupo a valorizarem a questão da economia interna e as oportunidades que a estabilidade política do país pode oferecer, como a possibilidade de empreender. Esse agrupamento, no entanto, tem a peculiaridade de possuir médias altas em muitas variáveis, as quais dispõem de diferentes enfoques. As médias altas em Personal Finances, Working Life, Lifestyle, People e Raising Children 
deixam claro que os países pertencentes a esse cluster proporcionam a experiência total nos mais diversos aspectos.

A variável Personal Finances é a de maior média no terceiro cluster, revelando um interesse por parte dos expatriados dos países deste grupo pela possibilidade de expandir seus rendimentos ao trabalhar nessas nações e de uma possibilidade maior de salvaguardar poupanças.

Assim, entende-se que o cluster 1 é formado por expatriados que vivem em países em que se valoriza mais o próprio estilo de vida, a qualidade de vida individual e familiar e os relacionamentos interpessoais do que os aspectos econômicos, sendo conveniente classificar este grupo sob a alcunha de "Grupo da Experiência de Vida". Enquanto que no cluster 2, apesar de a maior pontuação aludir à preocupação por parte desses expatriados no que eles podem obter das características da economia do país em que vivem, observa-se que, em razão das altas pontuações nos mais diversos aspectos, este grupo é composto por países que oferecem um contexto completo à expatriação, podendo ser nomeado como "Grupo da Experiência Total". O cluster 3, por sua vez, embora também possua uma tendência voltada aos aspectos econômicos, é mais voltado para as possibilidades de crescimento individual, sobretudo em relação à progressão na carreira. Convém, por isso, identificar esse grupo como o "Grupo da Perspectiva de Carreira".

\subsection{Discussão dos resultados}

A variável com maior média geral, considerando todos os grupos, é a variável People. Por obter médias altas (acima de 0,5) em todos os grupos, entende-se que a maioria dos expatriados concorda que a facilidade de se construir relações e de se integrar aos nativos é, sem dúvidas, essencial para que esse processo seja bem-sucedido. Tal resultado corrobora com Mendenhall e Oddou (1985) sobre a capacidade de se comunicar e de interagir do expatriado com os nativos e com Hill (2011) quando sugere que as empresas ofereçam três tipos de treinamento: cultural, linguístico e prático, antes da expatriação, como forma de facilitar esse processo de interação e aproximação junto aos nativos.

Tal importância pode ser um dos motivos dessa variável possuir baixo poder discriminante, conforme observado em seu alto valor de lambda de Wilks na tabela 1, ou melhor, já que, independente do agrupamento, a variável People é considerada importante, apresentando médias elevadas, ela não auxiliaria na discriminação entre os grupos de países. No grupo 2, "Grupo da Experiência Total", essa variável apresenta a mais alta média, reafirmando o caráter de experiência completa que este grupo proporciona aos expatriados, dessa vez relativa, especificamente, à integração no país hospedeiro.

Verificaram-se elevados valores referentes às médias da variável Setting Up em todos os grupos. Com destaque novamente para o cluster 2, "Grupo da Experiência Total", que apresentou a maior média e que, assim, contém os países em que os expatriados consideram mais importante o recebimento de algum auxílio financeiro na instalação inicial no país hospedeiro. Conforme ressaltaram Dutra (2012), Tanure e Duarte (2006), Hill (2011) e Dowling, Festing e Engle (2013), a Gestão da Expatriação considera necessário um suporte financeiro e infraestrutural antes, durante e depois da repatriação.

No que se refere, exclusivamente, à adaptação da família no país de expatriação, em especial no que diz respeito aos filhos dos expatriados, as variáveis Raising Children e Education and Childcare confirmam as afirmações teóricas Hill (2011) e Brewster, Sparrow e Vernon (2011). Primeiramente, no que concerne a variável Raising Children, observou-se que o segundo agrupamento apresentou médias muito altas, denotando a relevância do quão favorável é o ambiente para o crescimento saudável dos filhos. Os resultados da variável Education and Childcare apontam para uma maior representatividade deste quesito também no segundo cluster. Reafirmando o interesse dos expatriados desse grupo com todos os aspectos que envolvem a formação e o desenvolvimento dos filhos.

Hill (2011) e também Brewster, Sparrow e Vernon (2011) ainda destacam que a dificuldade de adaptação, por parte da família do expatriado, é uma das grandes causas para um insucesso ou falha na expatriação. Além dos filhos, a adaptação dos cônjuges também é bastante determinante para o sucesso da expatriação. A variável que trata dessa questão é Relationships, o grupo onde esta variável apresentou a maior média foi o grupo 1 . O resultado indica que o primeiro grupo é exatamente o que contém os países onde os expatriados mais valorizam o bem-estar, a qualidade de vida e, 
consequentemente, os relacionamentos, fazendo isso até em detrimento de uma melhor condição econômica.

Os expatriados compartilham um desejo pela mudança de vida, conforme afirmaram González e Oliveira (2011), muitas vezes, o desejo por viver essa nova experiência parte deles mesmos. Isso pode ser relacionado às características marcantes do cluster 1 , o "Grupo da Experiência de Vida". Embora nos outros grupos também se perceba essa tendência de busca pelo novo, principalmente em relação à progressão de carreira; no grupo 1, esse desejo é bem mais perceptível, em razão das altas médias da variável Lifestyle, que enfatiza saúde física e mental, qualidade de vida e bem-estar, confirmando a afirmação dos autores.

Conforme Lee (2011), deve-se considerar tanto a influência de fatores institucionais formais como informais em uma sociedade. Embora, dependendo da sociedade, um possa exercer maior influência do que o outro (Peng et al., 2009). Conforme destacado, no grupo 1, "Grupo da Experiência de Vida", as variáveis com maiores médias são Lifestyle e People, além de um destaque para a variável Relationships, conclui-se que os países desse agrupamento atraem mais expatriados que valorizam fatores institucionais informais, como os costumes e hábitos da sociedade, a exemplo da importância dada à qualidade de vida e aos relacionamentos interpessoais.

Outro fator desejado pelos profissionais que pensam em expatriação é o aumento de rendimentos. Segundo Hill (2011), as empresas precisam se atentar à necessidade de oferecerem salários atraentes que justifiquem passar por todo o processo de expatriação. Essa atração por elevação dos ganhos é perceptível por meio do destaque tanto da variável Personal Finances quanto da variável Local Economy e Working Life no terceiro grupo, "Grupo da Perspectiva de Carreira", confirmando a ambição desses profissionais em obter saltos de carreiras e de rendimentos. Isso corrobora com a explicação de Tertuliano (2016), que destaca que mesmo não sendo o único motivo que leva um indivíduo a aceitar viver e trabalhar em outro país, o fator econômico não pode ter sua importância subestimada.

O relatório Expat Explorer (2017) confirma que cerca de 1 em cada 5 expatriados foi morar em outro país em busca de aumento de rendimentos e cerca de 1 em cada 4 partiu em busca de perspectivas de progressão na carreira.
É exatamente no terceiro grupo, em razão de um destaque dado às três variáveis associadas aos aspectos econômicos (Personal Finances, Local Economy e Working Life), que se observa uma tendência de se enaltecer mais os fatores institucionais formais relacionados ao sistema econômico e sistemas legais, os quais asseguram maior estabilidade política e maior desenvolvimento econômico, criando maiores oportunidades de carreiras, de empreender e de guardar reservas financeiras, corroborando com Tertuliano (2016).

Uma maior confiabilidade nas instituições como um todo e, desta maneira, no sistema político-legal do país, é algo mais desejável a expatriados que buscam uma experiência completa e mais positiva, algo observado no segundo agrupamento. Outro fator importante a ser destacado é o fato de essa estabilidade política ser mais observada nos países desenvolvidos, sendo o grupo 2 exatamente o que possui mais países desenvolvidos em comparação aos demais, conforme apontado por Gallon, Cerutti e Maciel (2018).

\section{CONSIDERAÇÕES FINAIS}

A expatriação é um assunto complexo, o que torna imprescindível uma maior profissionalização da Gestão Internacional de Recursos Humanos (GIRH). É necessário se entender melhor o que desejam, o que precisam esses indivíduos que assumem, com admirável coragem, o desafio de viver e trabalhar em outro país, para isso, deve-se entender, também, a influência do ambiente institucional dos países sobre a vida desses expatriados e famílias, de forma a evitar o insucesso desse processo, o qual causa danos tanto à empresa quanto ao indivíduo e seus familiares.

No que se refere à perspectiva dos expatriados sobre os aspectos do ambiente institucional dos países que influenciam suas condições de vida nos países hospedeiros, observou-se que, embora dois grupos tenham enfatizado mais aspectos específicos, houve um grupo que obteve altos escores em diferentes aspectos e esse grupo foi identificado como o que proporciona a experiência completa aos expatriados, isto é, as melhores condições de vida. Mesmo nos grupos com tendências mais definidas, não se observam diferenças muito bruscas entre as médias, ou seja, não há a predominância total de maiores médias nas variáveis relativas a um aspecto em detrimento dos outros dois. 
No ranking geral, apresentado pelo próprio HSBC Expat no relatório HSBC Expat Explorer Broadening perspectives, notou-se então que os países que ocupavam as primeiras posições eram exatamente aqueles pertencentes ao "Grupo da Experiência Total", reafirmando a preferência dos expatriados pela experiência completa. Dessa forma, entende-se que, na perspectiva dos expatriados, os países que proporcionam boas condições de vida nos três fatores - econômicos, experiência e família, são melhores do que aqueles que proporcionam condições de vida extremamente favoráveis em um ou dois fatores, entretanto deixando a desejar aos demais.

Os objetivos específicos foram atendidos a partir da análise das classificações dos três grupos, destacando qual agrupamento possuía maior relação com cada uma das nove variáveis, qual possuía tendência relativamente definida que valorizasse um ou mais aspectos e como isso influenciava no sucesso da experiência de expatriação no país hospedeiro. E, também, pelo estudo de semelhanças e diferenças nas perspectivas dos expatriados sobre cada um dos 46 países em cada um dos três fatores de forma a agrupar os países hospedeiros de acordo com as tendências mais marcantes apontadas pelos expatriados, discutindo ainda o que cada grupo julga mais importante ao estabelecimento favorável, não somente do indivíduo, mas, também, de sua família.

A maior dificuldade do estudo foi em relação à falta de detalhamento acerca do método adotado pelo Banco HSBC para a realização da pesquisa apresentada no relatório HSBC Expat Explorer Broadening perspectives, de 2017. Para estudos futuros, recomenda-se a realização de uma pesquisa qualitativa com entrevistas a expatriados. Outra sugestão seria um estudo de caso, ou de múltiplos casos, em empresas que pratiquem a expatriação de forma a identificar como essas compreendem a necessidade de se analisar os fatores institucionais formais e informais dos países hospedeiros antes de decidirem sobre o envio de seus colaboradores a localidades onde se instalam suas subsidiárias estrangeiras.

\section{REFERÊNCIAS}

Brewster, C., Sparrow, P., \& Vernon, G. (2011). International human resource management. 3. ed. London: Chartered Institute of Personnel and Development.
Brunozi, A. C., Júnior, Antunes, J. A. V., Júnior, Kronbauer, C. A., \& Deboçã, L. P. (2016). Fatores institucionais determinantes das relações interorganizacionais: o caso da Rede Educar. Revista Estudo \& Debate, 23(1).

Caligiuri, P. M. (1997). Assessing expatriate success: Beyond just "being there". In Z. Aycan (Ed.), New approaches to employee management. (pp. 117-140). Elsevier Science/JAI Press.

Caligiuri, P. M., Hyland, M-A., \& Joshi, A. (1998). Testing a theoretical framework for examining the relationship between family adjustment to working in the host country. Journal of Applied Psychology, 83(4), 598-614.

Caligiuri, P. M. (2000). Selecting expatriates for personality characteristics: a moderating effect of personality on the relationship between host national contact and cross-cultural adjustment. Management International Review, 40(1), 61-80.

Carpes, A. M., Scherer, F. L., Lütz, C., Beuron, T. A, Borges, D. E., \& Santos, M. B. (2012). Gestão internacional de pessoas: considerações a partir do ajustamento internacional de expatriado na China e na Espanha. Internext - Revista Eletrônica de Negócios da ESPM, 7(1), 88-122.

Corrar, L. J.; Paulo, E., \& Dias, J. M., Filho (Coord.). (2014). Análise multivariada: para os cursos de administração, ciências contábeis e economia. São Paulo: Atlas.

Cota, M. S. G., Emmendoerfer, M. L., Reis, A. C. G., \& Silva, L. L. (2015). Processo de Adaptação de Executivos Expatriados no Brasil: um estudo sobre a atuação do profissional de Secretariado Executivo em uma multinacional de origem alemã. Revista de Gestão e Secretariado - GeSec, 6(1), 74-98.

Dowling, P. J., Festing, M., Engle, A. D. (2013). International Human Resource Management. 6a ed. London: Cengage Learning.

Dutra, J. S. (2012). Gestão de pessoas: modelos, processos, tendências e perspectivas. 11ạ ed. São Paulo: Atlas.

Fávero, L. P. L., Belfiore, P. P., Silva, F. L. da, \& Chan, B. L. (2009). Análise de dados: modelagem multivariada para tomada de decisões. Rio de Janeiro: Elsevier. 
FINACCORD, Finaccord Expatriate Base. (2018). Global expatriates: size, segmentation and forecast for the worldwide market, report prospectus. London. Recuperado de: https://www.finaccord.com/Home/About-Us/PressReleases/Global-Expatriates-Size,-Segmentation-andForecas.pdf.

Fonseca, J. J. S. (2002). Metodologia da pesquisa científica. Fortaleza: UECE.

Gallon, S., Cerutti, P. S., Maciel, A. C., \& Oliva, E. C. (2017). Políticas e Práticas do Processo de Expatriação: Um Estudo de Caso em uma Multinacional Brasileira. Revista Gestão Organizacional, 10(3), 79-101.

Gallon, S., Fraga, A. M., \& Antunes, E. D. (2017). Conceitos e Configurações de Expatriados na Internacionalização Empresarial. REAd. Revista Eletrônica de Administração, 23 (N. Especial), 29-59.

González, J. M. R.; Oliveira, J. A. (2011). Os efeitos da expatriação sobre a identidade: estudo de caso. Caderno EBAPE.BR, Rio de Janeiro, 9(4), 1122-1135.

Hair, J. F., Jr., Anderson, R. E., Tatham, R. L., \& Black, W. C. (2005). Análise multivariada de dados. 5a ed. Porto Alegre: Bookman.

Harrison, D. A.; Shaffer, M. A.; Bhaskar-Shrinivas, P. (2004). Going places: roads more and less traveled in research on expatriate experiences. Research in Personnel and Human Resources Management, 23, 203-252.

Hill, C. W. L. (2011). International business: competing in the global marketplace. 8a ed. New York: McGraw-Hill/Irwin.

Lacombe, B. M. B., \& Chu, R. A. (2008). Políticas e práticas de gestão de pessoas: as abordagens estratégica e institucional. RAE-Revista de Administração de Empresas, 48(1), 25-35.

Lee, M-D. P. (2011). Configuration of external influences: the combined effects of instituions and stakeholders on corporate social responsability strategies. Journal of Business Ethics, 102(2), 281-298.

Mendenhall, M., \& Oddou, G. (1985). The dimensions of expatriate acculturation: a review. Academy of Management Review, 10 (1), 39-47.
Meyer, J. W., \& Rowan, B. (1977). Institutionalized organizations: formal structure as myth and ceremony. American Journal of Sociology, 83(2), 340363.

North, D. C. (1990). Instituions, institucional change and economic performance. Cambridge: Cambridge University Press.

Peng, M. W., Sun, S.L., Pinkham, B., \& Chen, H. (2009). The instituion-based view as a third leg for a strategy tripod. The Academy of Management Perspectives, 23(3), 63-81.

Peng, M. W. (2002). Towards an instituition-based view of business strategy. Asia Pacific Journal of Management, 19(2), 251-267.

Peng, M. W. (2013). Global business. 3a ed. Cincinnati: South Western Cengage Learning.

Ranieri, A. (2018). Diversity management in three Latin American countries: an institutional perspective. ARLA. Academia Revista Latinoamericana de Administración, 31(2), 426-447, 2018.

Rossetto; C. R., \& Rossetto, A. M. (2005). Teoria institucional e dependência de recursos na adaptação organizacional: uma visão complementar. RAEEletrônica, 4(1), 25-35.

Sambavisan, M., Sadoughi, M., \& Esmaeilzadeh, P. (2017). Investigating the factors influencing cultural adjustment and expatriate performance: the case of Malaysia, International Journal of Productivity and Performance Management, 66(8), 1002-1019.

Scott, W. R. (2014). Institutions and Organizations: Ideas, Interests, and Identities. 4a ed. London: Sage Publications Ltd.

Selznick, P. (1971). A Liderança na Administração: uma interpretação sociológica. Tradução de Arthur Pereira e Oliveira Filho. Rio de Janeiro: Fundação Getúlio Vargas.

Snell, S., \& Bohlander, G. (2013). Administração de recursos humanos. Tradução de Maria Lúcia G. Leite Rosa e Solange Aparecida Visconti. 2a ed. São Paulo: Cengage Learning.

Tanure, B., \& Duarte, R. G. (Orgs.) (2006). Gestão internacional. São Paulo: Saraiva. 
Perspectiva dos Expatriados sobre Aspectos do Ambiente Institucional que Influenciam suas Condições de Vida nos Países Hospedeiros

Tertuliano, I. W. (2016). Processo de Expatriação de Voleibolistas: concepções bioecológicas. 2016. 284 f. Tese (Doutorado de Desenvolvimento Humano e Tecnologias) - Instituto de Biociências, Universidade Estadual Paulista, Rio Claro.
Zhang, N., \& Rentz, A. L. (1996). Intercultural adaptation among graduate students from the people's republic of China. College Student Journal, 30(3), 321-329.

Mariana Rangel Moraes - Universidade Federal do Ceará -UFC, Ceará, (Brasil). E-mail: marianarangel7@gmail.com Orcid id: https://orcid.org/0000-0001-8568-2896

Márcia Zabdiele Moreira - Universidade Federal do Ceará -UFC, Ceará, (Brasil). E-mail: marciazabdiele@ufc.br Orcid id: https://orcid.org/0000-0001-8274-0034

Diego de Queiroz Machado - Universidade Federal do Ceará -UFC, Ceará, (Brasil). E-mail: diegomachado@ufc.br Orcid id: https://orcid.org/0000-0002-3570-8864

Daniel Barboza Guimarães - Universidade Federal do Ceará -UFC, Ceará, (Brasil). E-mail: barbozadan@hotmail.com Orcid id: https://orcid.org/0000-0001-6966-7194 


\title{
EXPATRIATES' PERSPECTIVE ON ASPECTS OF THE INSTITUTIONAL ENVIRONMENT THAT INFLUENCE THEIR LIVING CONDITIONS IN THE HOST COUNTRIES
}

\author{
Mariana Rangel Moraes, Márcia Zabdiele Moreira, Diego de Queiroz Machado \& Daniel Barboza Guimarães \\ Universidade Federal do Ceará -UFC, Ceará, (Brasil)
}

\begin{tabular}{l}
\hline ARTICLE DETAILS \\
Article history: \\
Received: 17 september 2020 \\
Accepted: 01 october 2021 \\
Available online october: 27 th 2021 \\
Double Blind Review System \\
Scientific Editor \\
Ilan Avrichir \\
\hline Keywords \\
Expatriation \\
Living Conditions Abroad \\
Institutional Environment \\
Host Countrie
\end{tabular}

\section{ABSTRACT}

Objective: The study aimed to analyze the expatriates' perspective on aspects of the institutional environment that influence their living conditions in the host countries.

Method: It was a quantitative research, with secondary data obtained from the HSBC Expat Explorer Broadening perspectives report, published in 2017. A cluster analysis was carried out to group countries on nine variables related to economic, experience and family's.

Main results: The results were validated through discriminant analysis. It was found that there are three groups, one with a greater appreciation of the aspects of experience, another with an equivalent appreciation of the aspects of experience and economics and another with a greater appreciation of aspects of family.

Relevance/originality: As living conditions in other countries can influence the expatriate's intercultural adjustment and the duration of expatriation, and may even culminate in an early repatriation, this study is relevant and original because it relates themes that are usually studied separately: institutional factors of countries, living conditions in countries and expatriation.

Theoretical/methodological contributions: The study expands the discussions by considering the perspective of expatriates on how the institutional factors of the host countries influence the living conditions they will have elsewhere. 


\title{
LA PERSPECTIVA DE LOS EXPATRIADOS SOBRE ASPECTOS DEL ENTORNO INSTITUCIONAL QUE INFLUYEN EM SUS CONDICIONES DE VIDA EM LOS PAÍSES ANFITRIONES EL EXTERIOR
}

\author{
Mariana Rangel Moraes, Márcia Zabdiele Moreira, Diego de Queiroz Machado \& Daniel Barboza Guimarães
} Universidade Federal do Ceará -UFC, Ceará, (Brasil)

\begin{tabular}{l} 
DETALLES DEL ARTÍCULO \\
\hline Historia del Artículo: \\
Recibido: 17 de septiembre de 2020 \\
Aceptado: 01 de octubre de 2021 \\
Disponible en línea: 27 de octubre 2021 \\
Double Blind Review System \\
Editor Científico \\
Ilan Avrichir \\
\hline
\end{tabular}

\section{Palabras-clave:}

Internacionalización

Empresa familiar

Percepción del riesgo

\section{RESUMEN}

Objetivo: El estudio tuvo como objetivo analizar la perspectiva de los expatriados sobre aspectos del entorno institucional de los países que influyen em sus condiciones de vida en el exterior.

Método: Se trata de una investigación cuantitativa, con datos secundarios obtenidos del informe HSBC Expat Explorer Ampliación de perspectivas, publicado en 2017. Se realizó un análisis de conglomerados para agrupar países sobre nueve variables relacionadas con la economía, la experiencia y de la familia. Los resultados obtenidos fueron validados mediante análisis discriminante.

Resultados principales: Se encontró la existencia de tres grupos, uno con una mayor valoración de los aspectos de la experiencia, otro con una valoración equivalente de los aspectos de la experiencia y la economía y otro con una mayor valoración de los aspectos de la familia.

Relevancia /originalidad: Dado que las condiciones de vida en otros países pueden influir en el ajuste intercultural del expatriado y la duración de la expatriación, e incluso pueden culminar en una repatriación temprana, este estudio es relevante y original porque relaciona temas que generalmente se estudian por separado: factores institucionales de los países, condiciones de vida en los países y expatriación.

Contribuciones teóricas/metodológicas: El estudio amplía las discusiones al considerar la perspectiva de los expatriados sobre cómo los factores institucionales de los países de acogida influyen en las condiciones de vida que tendrán en otros lugares.

\section{Como citar este artigo:}

Moraes, M. R., Moreira, M. Z., Machado, D. de Q., \& Guimarães, D. B. (2022). Perspectiva dos Expatriados sobre Aspectos do Ambiente Institucional que Influenciam suas Condições de Vida nos Países Hospedeiros. Internext, 17(1), 64-80. https://doi.org/10.18568/internext.v17i1.631 